\title{
Control of Flexible Joint Manipulator via Reduced Rule-Based Fuzzy Control with Experimental Validation
}

\author{
Mojtaba Rostami Kandroodi, ${ }^{1}$ Mohammad Mansouri, ${ }^{2}$ \\ Mahdi Aliyari Shoorehdeli, ${ }^{3}$ and Mohammad Teshnehlab ${ }^{2}$ \\ ${ }^{1}$ Control and Intelligent Processing Center of Excellence, School of Electrical and Computer Engineering, University of Tehran, \\ Tehran, Iran \\ ${ }^{2}$ Department of Control Engineering, Faculty of Electrical Engineering, K. N. Toosi University of Technology, Tehran, Iran \\ ${ }^{3}$ Department of Mechatronics Engineering, Faculty of Electrical Engineering, K.N. Toosi University of Technology, Tehran, Iran
}

Correspondence should be addressed to Mojtaba Rostami Kandroodi, m.rostami.k@ece.ut.ac.ir

Received 5 August 2011; Accepted 20 September 2011

Academic Editor: L. Mikhailov

Copyright ( $\odot 2012$ Mojtaba Rostami Kandroodi et al. This is an open access article distributed under the Creative Commons Attribution License, which permits unrestricted use, distribution, and reproduction in any medium, provided the original work is properly cited.

\begin{abstract}
A novel structure of fuzzy logic controller is presented for trajectory tracking and vibration control of a flexible joint manipulator. The rule base of fuzzy controller is divided into two sections. Each section includes two variables. The variables of first section are the error of tip angular position and the error of deflection angle, while the variables of second section are derivatives of mentioned errors. Using these structures, it would be possible to reduce the number of rules. Advantages of proposed fuzzy logic are low computational complexity, high interpretability of rules, and convenience in fuzzy controller. Implementing of the fuzzy logic controller on Quanser flexible joint reveals efficiency of proposed controller. To show the efficiency of this method, the results are compared with LQR method. In this paper, experimental validation of proposed method is presented.
\end{abstract}

\section{Introduction}

The trajectory tracking control of robotic manipulators with joint flexibility has received considerable attention, owing to the complexity of the problem. Many robots incorporate harmonic drives for speed reduction, and it is known that such drives introduce tensional elasticity into the joints [1]. Industrial robots generally have elastic elements in the transmission systems, which may result in the occurrence of tensional vibrations when a fast response is required. For many manipulators, joint elasticity may arise from several sources, such as elasticity in gears, belts, tendons, bearings, hydraulic lines, and so forth, and may limit the speed and dynamic accuracy achievable by control algorithms designed assuming perfect rigidity at joints. A proper choice of mathematical model for a control system design is a crucial stage in the development of control strategies for any system. This is particularly true for robotic manipulators due to their complicated dynamics [2].

Experimental evidence suggests that joint flexibility should be taken into account in both modelling and control of manipulators if high performance is to be achieved. To model this elastic behaviour in the joints, the link is considered as connected to rotor through a tensional spring of stiffness $K$. The introduction of joint flexibility in the robot model considerably complicates the equations of motion. In particular, the order of the related dynamics becomes twice that of the rigid robots, and the number of degrees of freedom is larger than the number of inputs, making the control task difficult.

Research on the dynamic modelling and control of flexible robots has received increased attention in the last decades. A first step towards designing an efficient control strategy for manipulators with flexible joints must be aimed at developing dynamic models that can characterize the flexibility of the joints accurately. The controller design that minimizes the effects of the flexible displacements in lightweight robots is highly demanded in many industrial and space applications that require accurate trajectory control. In control applications of robot, manipulators with flexible arms are targeted either to reach a target position or to follow a prescribed 
trajectory. In the first case to reach a target position, a short settling time is desired while a large robot arm displacement is planned in the second case to follow a prescribed trajectory. In both cases, strong control actions are applied to the robot arm, and, as a result, undesired behaviours could appear if vibrations induced in the robot arm are not considered [3].

The control issue of the flexible joint is to design the controller so that link of robot can reach a desired position or track a prescribed trajectory precisely with minimum vibration to the link. In order to achieve these objectives, various methods using different technique have been proposed such as follow: linear quadratic regulation (LQR) control [4], adaptive output-feedback controller based on a backstepping design [5-7], nonlinear control based on the feedback linearization technique and the integral manifold technique $[8,9]$, robust control based on PD control [10] and robust $\mathrm{H} \infty$ control [11], fuzzy control, PD fuzzy and neural network [12-15], optimal control [16, 17], and so forth [2, 18-23].

In this paper, a novel structure of fuzzy logic controller is designed to control trajectory tracking and vibration of a flexible joint manipulator system. The rule base of fuzzy controller is divided into two sections. Each section includes two variables. The variables of the first section are the error of tip angular position and the error of deflection angle, while the variables of the second section are derivatives of mentioned errors. Using these structures, it would be possible to reduce the number of rules. The proposed fuzzy logic controller is implemented on the Quanser flexible joint to show efficiency of proposed controller.

The paper is organized as follows. The flexible joint manipulators are described in Section 2. Section 3 explains modelling of the flexible joint manipulator. Section 4 is focused on introductory to fuzzy logic controller. The proposed fuzzy logic controller are described in Section 5. Section 6 illustrates the implementation results. Finally, the conclusion is presented in Section 7.

\section{The Flexible Joint Manipulator System}

The flexible joint manipulator system considered in this work is shown in Figure 1, where $\theta$ is the tip angular position and $\alpha$ is the deflection angle of the flexible link. The base of the flexible joint manipulator which determines the tip angular position of the flexible link is driven by servomotor, while the flexible link will response based on base movement. The deflection of link will be determined by the flexibility of the spring as their intrinsic physical characteristics [24].

\section{Modelling of the Flexible Joint Manipulator}

This section provides a brief description on the modeling of the flexible joint manipulator system, as a basis of a simulation environment for development and assessment of the nonlinear control. The Euler-Lagrange formulation is considered in characterizing the dynamic behavior of the system. Considering the motion of the flexible joint system on

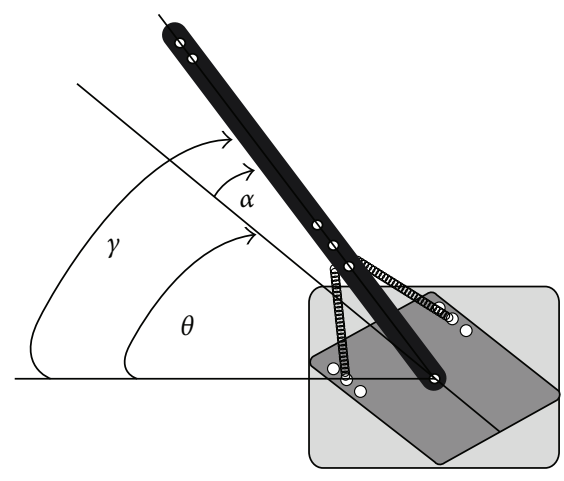

FIGURE 1: Description of the flexible joint manipulator system [20].

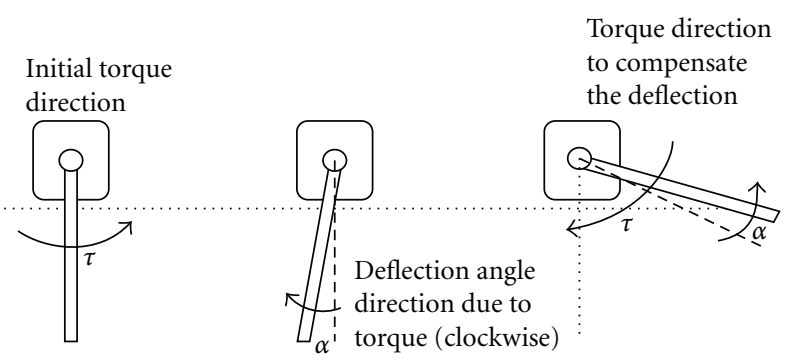

(a)

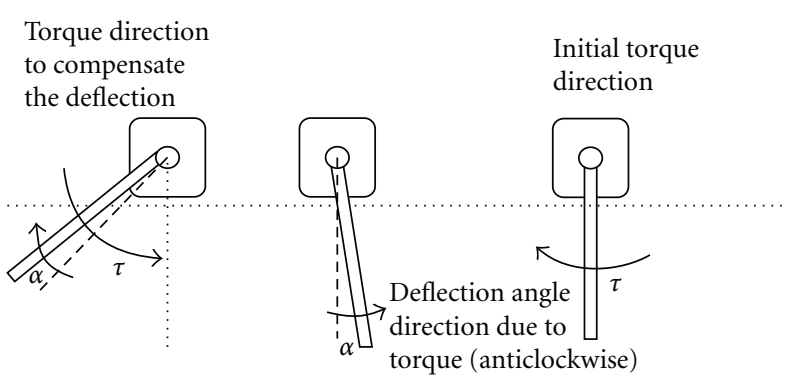

(b)

Figure 2: (a) Direction of torque to reduce deflection angle when link moves anticlockwise. (b) Direction of torque to reduce deflection angle when link moves clockwise.

a two-dimensional plane, the potential energy of the spring can be formulated as [24]

$$
V=\frac{1}{2} K_{\text {stiff }} \alpha^{2},
$$

where $K_{\text {stiff }}$ is the joint stiffness. The kinetic energies in the system arise from the moving hub and flexible link can be formulated as

$$
T=\frac{1}{2} J_{\mathrm{eq}} \dot{\theta}^{2}+\frac{1}{2} J_{\operatorname{Arm}}(\dot{\theta}+\dot{\alpha})^{2},
$$

where $J_{\text {eq }}$ and $J_{\text {Arm }}$ are the equivalent inertia and total link inertia, respectively. To obtain a closed-form dynamic model of the flexible joint, the energy expressions in (1) and (2) are applied to formulate the Lagrangian; that is,

$$
L=T-V=\frac{1}{2} J_{\mathrm{eq}} \dot{\theta}^{2}+\frac{1}{2} J_{\text {Arm }}(\dot{\theta}+\dot{\alpha})^{2}-\frac{1}{2} K_{\text {stiff }} \alpha^{2} .
$$




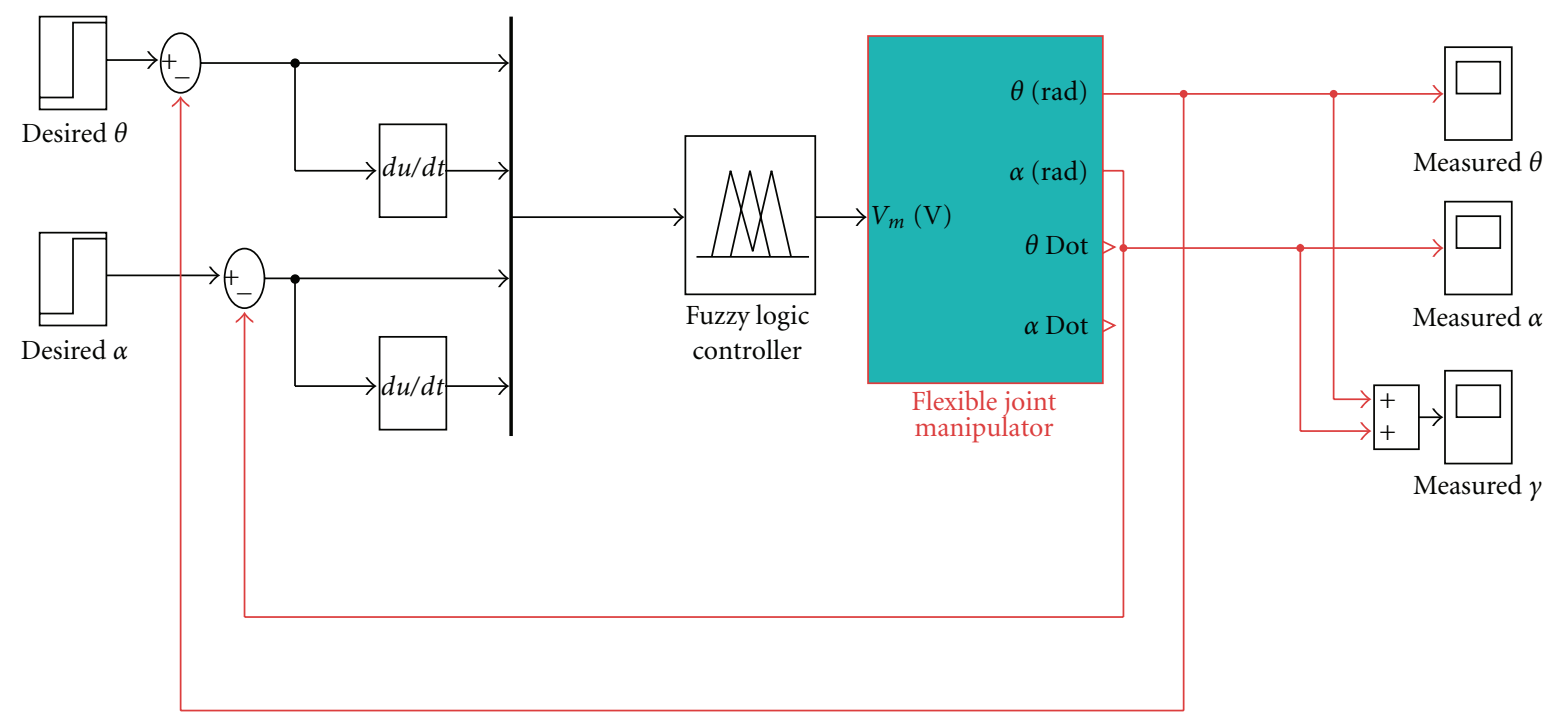

FIgURE 3: Block diagram of fuzzy logic control for flexible joint manipulator.

TABLE 1: System parameters.

\begin{tabular}{lcc}
\hline Symbol & Quantity & Value \\
\hline$R_{m}$ & Armature resistance $(\Omega)$ & 2.6 \\
$K_{m}$ & Motor back-EMF constant $(\mathrm{V} \cdot \mathrm{rad} / \mathrm{S})$ & 0.00767 \\
$K_{t}$ & Motor torque constant $(\mathrm{N} \cdot \mathrm{M} / \mathrm{A})$ & 0.00767 \\
$J_{\text {Arm }}$ & Total arm inertia $\left(\mathrm{kg} \cdot \mathrm{m}^{2}\right)$ & 0.0035 \\
$J_{\text {eq }}$ & Equivalent inertia $\left(\mathrm{kg} \cdot \mathrm{m}^{2}\right)$ & 0.0026 \\
$K_{g}$ & High gear ratio & $14: 5$ \\
$K_{\text {stiff }}$ & Joint stiffness & 1.2485 \\
$B_{\text {eq }}$ & Equivalent viscous damping & 0.004 \\
$\eta_{g}$ & (N.M.S/rad) & 0.9 \\
$\eta_{m}$ & Gearbox efficiency & 0.69 \\
\hline
\end{tabular}

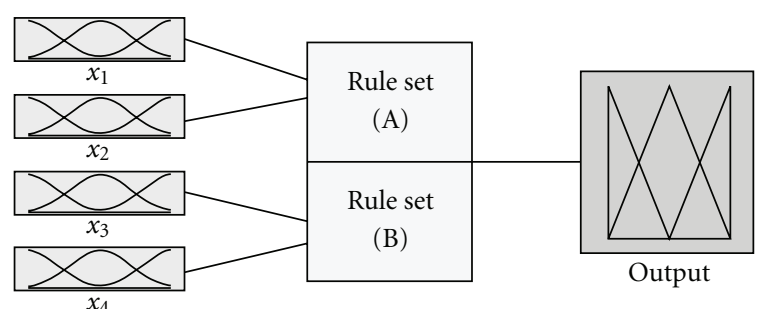

FIGURE 4: Structure of designed fuzzy logic controller.

Two generalized coordinates are $\theta$ and $\alpha$. Let the generalized torque corresponding to the generalized tip angle be $T_{\text {output }}-B_{\text {eq }} \dot{\theta}$. Use Lagrangian's equation as follows:

$$
\begin{gathered}
\frac{\partial}{\partial t}\left(\frac{\partial L}{\partial \dot{\theta}}\right)-\frac{\partial L}{\partial \theta}=T_{\text {output }}-B_{\text {eq }} \dot{\theta}, \\
\frac{\partial}{\partial t}\left(\frac{\partial L}{\partial \dot{\alpha}}\right)-\frac{\partial L}{\partial \alpha}=0 .
\end{gathered}
$$

TABLE 2: Rule base of fuzzy controller.

\begin{tabular}{lccc}
\hline$e_{1} \Rightarrow$ & $N$ & $Z$ & $P$ \\
\hline$e_{2} \Downarrow$ & $Z$ & $P$ & $P$ \\
\hline$N$ & $N$ & $Z$ & $P$ \\
$Z$ & $N$ & $N$ & $Z$ \\
$P$ & $N$ & $Z$ & $P$ \\
\hline$\dot{e}_{1} \Rightarrow$ & $Z$ & $P$ & $P$ \\
$\dot{e}_{2} \Downarrow$ & $N$ & $Z$ & $P$ \\
\hline$N$ & $N$ & $N$ & $Z$ \\
$Z$ & & & \\
$P$ & & & \\
\hline
\end{tabular}

The equation of motion is obtained as below:

$$
\begin{gathered}
J_{\mathrm{eq}} \ddot{\theta}+J_{\mathrm{Arm}}(\ddot{\theta}+\ddot{\alpha})=T_{\text {output }}-B_{\mathrm{eq}} \dot{\theta}, \\
J_{\mathrm{Arm}}(\ddot{\theta}+\ddot{\alpha})+K_{\text {stiff }} \alpha=0,
\end{gathered}
$$

where $B_{\mathrm{eq}}$ is the equivalent viscous damping and $T_{\text {output }}$ is the output torque on the load from the motor, defined as

$$
T_{\text {output }}=\frac{\eta_{m} \eta_{g} K_{t} K_{g}\left(V_{m}-K_{g} K_{m} \dot{\theta}\right)}{R_{m}},
$$

where $\eta_{m}$ is the motor efficiency, $\eta_{g}$ is the gearbox efficiency, $K_{t}$ is the motor torque constant, $K_{g}$ is the high gear ratio, $K_{m}$ is the motor back-EMF constant, and $R_{m}$ is the armature resistance. The linear model of the uncontrolled system can be represented in a state-space form as shown in (7); that is,

$$
\begin{gathered}
\dot{x}_{1}=x_{3}, \\
\dot{x}_{2}=x_{4}, \\
\dot{x}_{3}=a x_{2}+b x_{3}+c u, \\
\dot{x}_{4}=d x_{2}+f x_{3}-c u,
\end{gathered}
$$




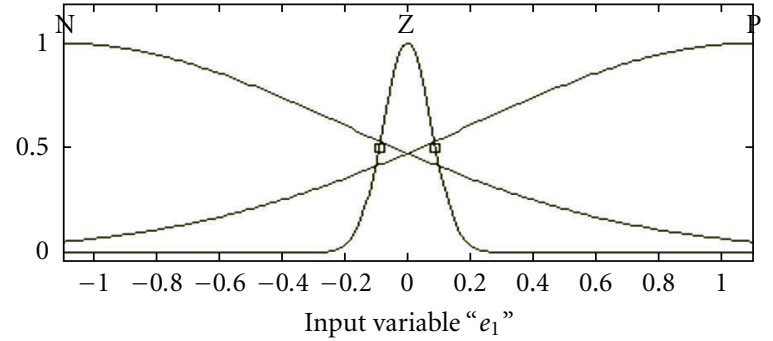

(a)

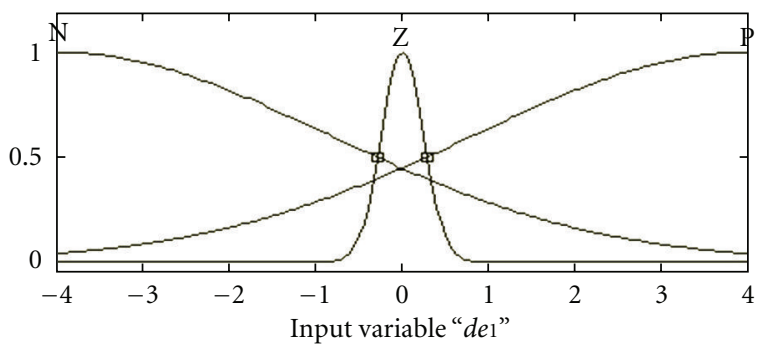

(c)

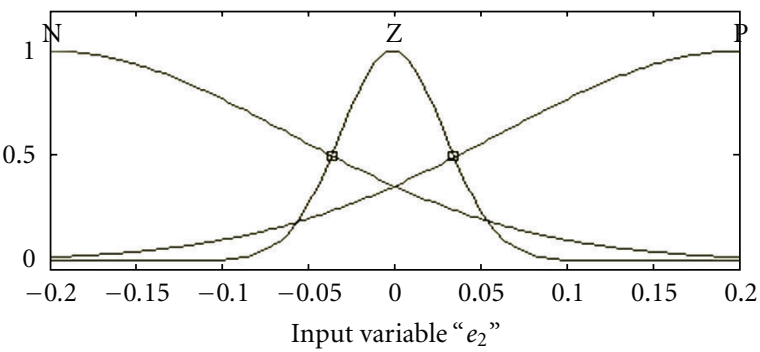

(b)

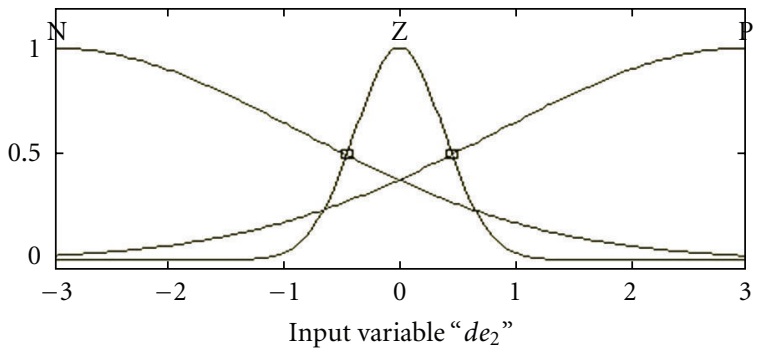

(d)

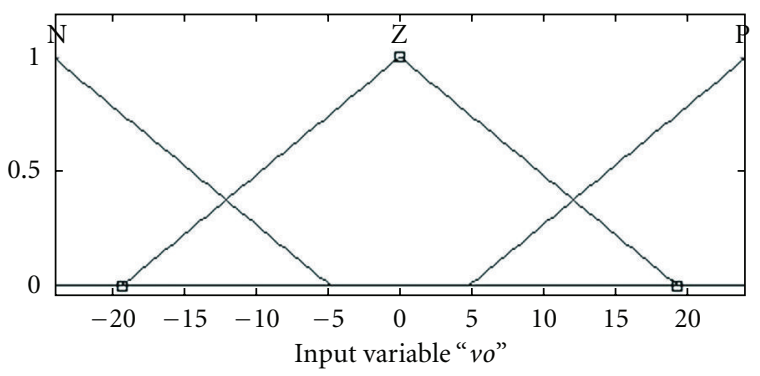

(e)

FIGURE 5: Membership functions of inputs and output for fuzzy logic controller.

where $x=\left[\begin{array}{llll}\theta & \alpha & \dot{\theta} & \dot{\alpha}\end{array}\right]^{T}$ and $a, b, c, d$, and $f$ are given as

$$
\begin{gathered}
a=\frac{K_{\mathrm{stiff}}}{J_{\mathrm{eq}}}, \\
b=\frac{-\eta_{m} \eta_{g} k_{t} k_{m} K_{g}^{2}+B_{\mathrm{eq}} R_{m}}{J_{\mathrm{eq}} R_{m}}, \\
c=\frac{\eta_{m} \eta_{g} K_{t} K_{g}}{J_{\mathrm{eq}} R_{m}}, \\
d=-\frac{K_{\mathrm{stiff}}\left(J_{\mathrm{eq}}+J_{\mathrm{Arm}}\right)}{J_{\mathrm{eq}} J_{\mathrm{Arm}}}, \\
f=\frac{\eta_{m} \eta_{g} k_{t} k_{m} K_{g}^{2}+B_{\mathrm{eq}} R_{m}}{J_{\mathrm{eq}} R_{m}} .
\end{gathered}
$$

In (7), the input $u$ is the input voltage of the servomotor, $V_{m}$ which determines the flexible joint manipulator base movement. In this study, the values of the parameters are defined as Table 1. Directions of torque to reduce the deflection angle when link moves anticlockwise and clockwise are shown in Figures 2(a) and 2(b), respectively.

\section{Fuzzy Logic Controller}

The first studies in the field of fuzzy systems and control have been making a big progress motivated by the practical success achieved in industrial process control applications. Fuzzy systems can be used either as open-loop controllers or as closed-loop controllers, as shown in Figure 3. When used as a closed-loop controller, the fuzzy system measures the outputs of the process and takes control actions on the process continuously. Applications of fuzzy systems in industrial processes belong to this category. The fuzzy controller uses a form of quantification of imprecise information (input fuzzy sets) to generate by an inference scheme, which is based on a knowledge base of control force to be applied on the system.

Two of the difficulties in the design of fuzzy control systems are to generate the membership functions and choice of the fuzzy rules. In fact, the decision-making logic is the way in which the controller output is generated. It uses the input fuzzy sets, and the decision is taken according to the values of the inputs. Moreover, the knowledge base comprises knowledge of application domain and the attendant control goals. 


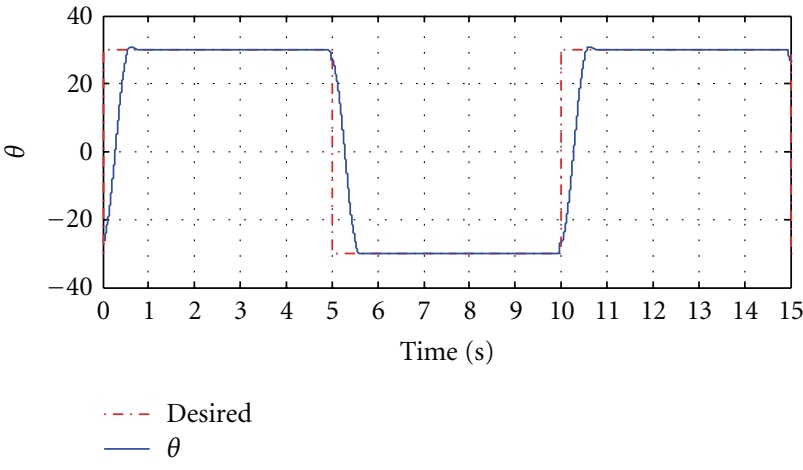

(a)

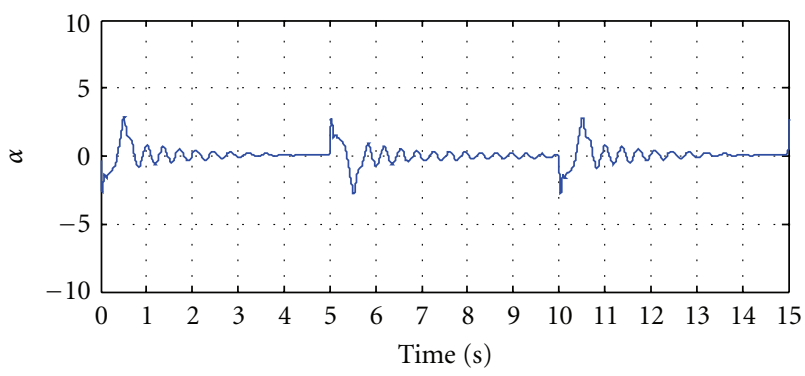

(b)

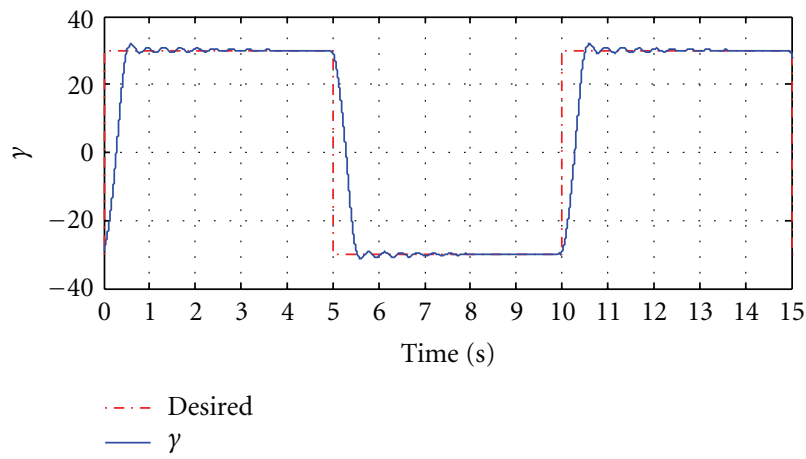

(c)

FIgURE 6: (a) Tip angular position of the flexible joint manipulator, (b) deflection angle of the flexible joint manipulator, (c) summation of the two signals of (a) and (b).

\section{Proposed Fuzzy Logic Controller}

The proposed fuzzy logic controller including four inputs; the error of tip angular position " $e_{1}$," the error of deflection angle " $e_{2}$," and their derivatives " $d e_{1}$ " and " $d e_{2}$ ". The input voltage of the servomotor is considered as a output of fuzzy controller. For each input and output variable, three membership functions in the names of "positive," "negative," and "Zero" are defined. Figure 4 shows the structure of designed fuzzy logic controller.

As Figure 4 shows the rule base of fuzzy controller is divided to two small sections, each section contains 9 rules. Using these sections reduced the number of rules from 81 rules to 18 rules. So, not only computational complexity decreases but also the interpretability of rule base increases. Another advantage of proposed rule base is that the implementation of fuzzy controller is more convenient.

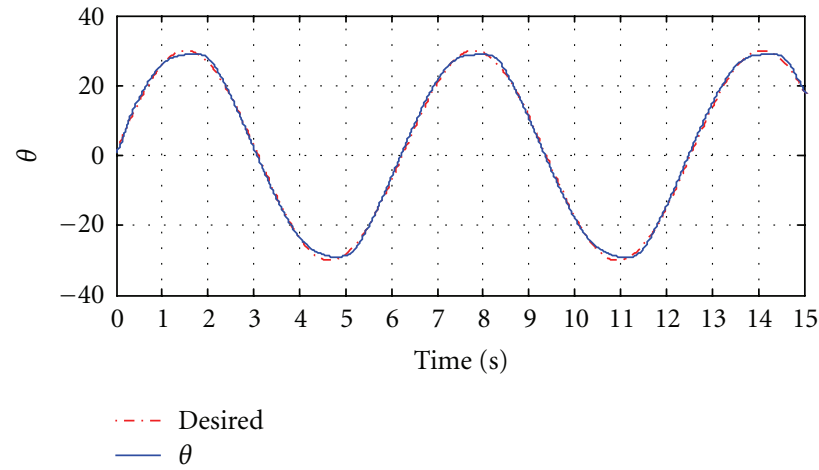

(a)

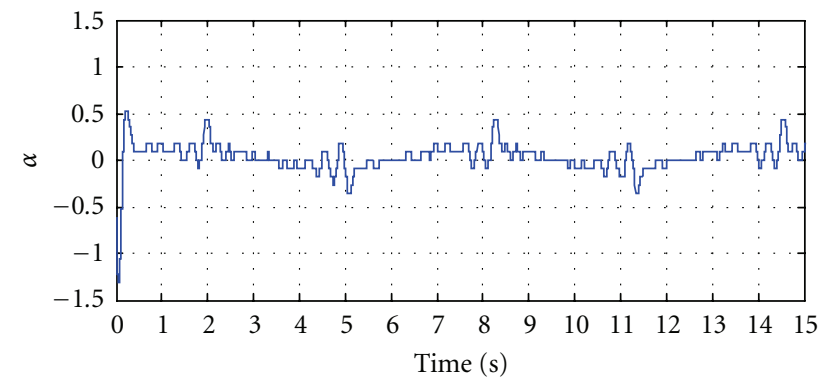

(b)

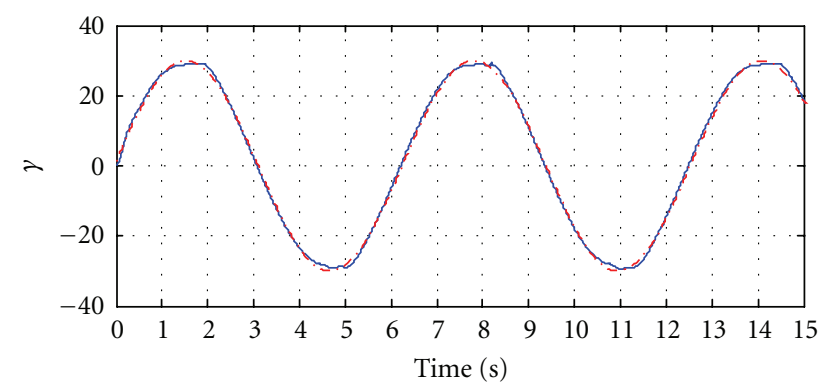

$\begin{array}{ll}- & \gamma \\ -\cdots & \text { Desired }\end{array}$

(c)

FIgURE 7: (a) Tip angular position of the flexible joint manipulator, (b) deflection angle of the flexible joint manipulator, (c) summation of the two signals of (a) and (b).

Figure 5 demonstrates membership function of four inputs and one output of the suggested controller. Because the model of system is nonminimum phase, the effect of tip angular position's error and deflection angle's error as two inputs are reverse of each other. Therefore, when tip angular position's error and deflection angle's error are in the same sign, the input voltage of the servomotor should be zero, and, when they are in different sign, the input voltage, depending on conditions, should be positive or negative. Table 1 shows rule base of the proposed fuzzy logic controller. The two mentioned sections are observable in Table 2.

\section{Implementation Results}

In this investigation, the designed fuzzy controller is applied to the flexible joint manipulator of the Quanser experimental 


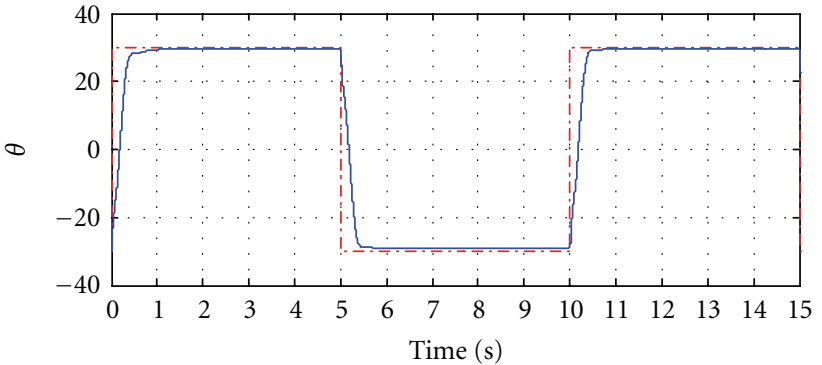

$\cdot-\cdot-$ Desired

$-\theta$

(a)

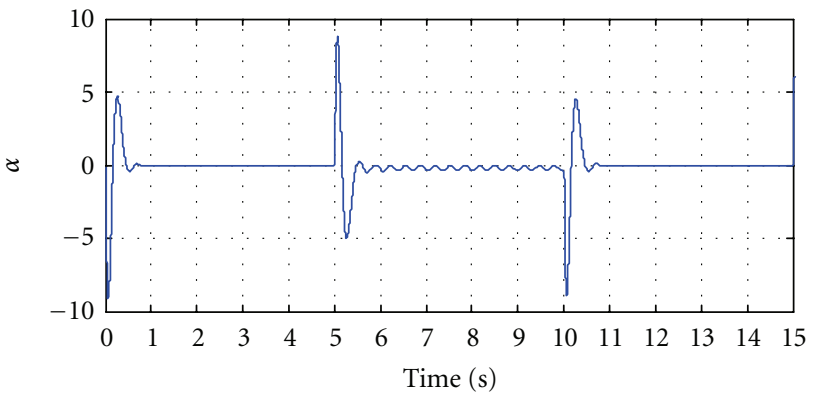

(b)

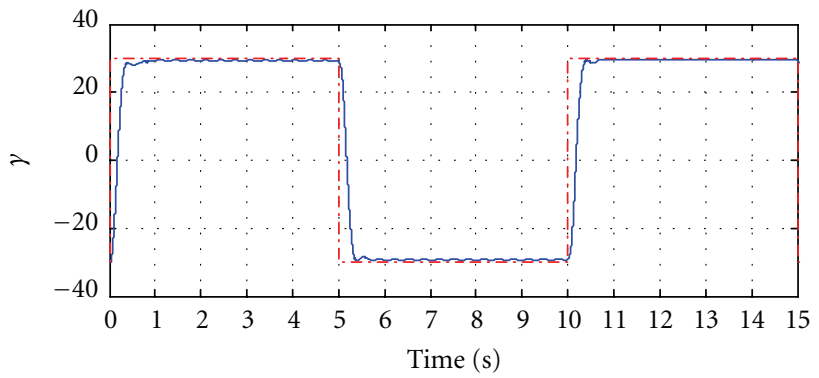

$-\gamma$

-... Desired

(c)

FIGURE 8: (a) Tip angular position of the flexible joint manipulator, (b) deflection angle of the flexible joint manipulator, (c) summation of the two signals of (a) and (b).

set in order to testify the trajectory tracking capability of it. The input is applied at the tip angular of flexible joint manipulator. The tip angular position of the flexible joint manipulator is required to follow a trajectory of square pulse with amplitude of 30 degrees and the frequency of $0.1 \mathrm{~Hz}$. As Figure 6(a) shows, the flexible joint manipulator tracks the desire trajectory. Figure 6(b) demonstrates deflection angle. It is observable that deflection angle amplitude's range is satisfactory and it has a suitable damping ratio. The summation of two signals, $\gamma$, is shown in Figure 6(c). It has very important concept. It shows the behaviour of flexible joint with respect to fix-point of system. As the figure demonstrates, there is not any unacceptable overshoot and undershoot in $\gamma$. So, the designed controller with 18 rules can satisfy desired specifications of system.

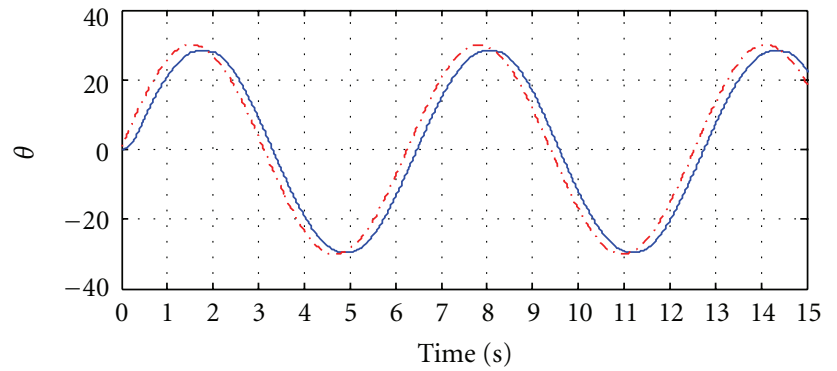

-. - Desired

$-\theta$

(a)

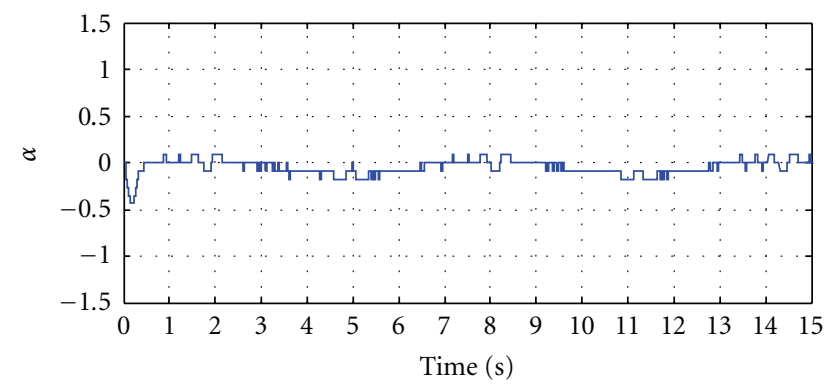

(b)

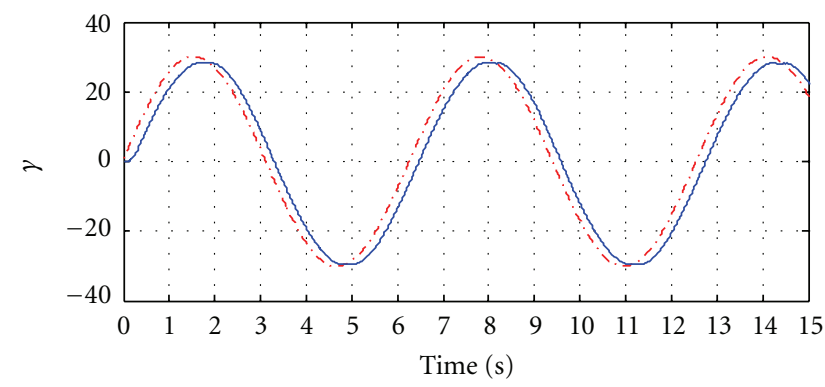

$-\gamma$

-... Desired

(c)

FIGURE 9: (a) Tip angular position of the flexible joint manipulator, (b) deflection angle of the flexible joint manipulator, (c) summation of the two signals of (a) and (b).

To show the efficiency of the designed controller, sinusoidal trajectory is considered as another desired trajectory which the tip angular position of the flexible joint manipulator should track. Figures 7(a) and 7(b) demonstrate that tip angular position follows the desired trajectory satisfactorily and deflection angle is in the acceptable range, respectively. As Figure 7(c) shows, the summation of two mentioned signals, $\gamma$, is suitable.

The LQR controller is applied to the system for comparison with the proposed fuzzy controller. The results for the first input are illustrated in Figures 8(a), 8(b), and 8(c).

As Figure 8(b) shows, there is a significant overshoot in the deflection angle which is not desirable. Figure 7(c) demonstrated the flexible joint manipulator did not track exactly and there is tracking error in the designed LQR controller. 
Figures 9(a), 9(b), and 9(c) illustrated the results of applying sinusoidal trajectory as the second desired trajectory to the LQR controller.

As results show, there is a significant tracking error in flexible joint manipulator trajectory which is not desirable at all. Comparison of the proposed fuzzy controller with LQR controller reveals the efficiency of proposed controller.

The proposed reduced rule-based fuzzy control is effective and applicable than the conventional fuzzy control. Reducing fuzzy rules is helpful to decrease the computational time and computational resources.

\section{Conclusion}

In this paper, a novel structure of fuzzy logic controller was presented for trajectory tracking and vibration control of a flexible joint manipulator. Dividing rule base into two sections, such that each contains 9 rules, reduced the number of rules from 81 rules to 18 rules. The proposed fuzzy logic controller decreased computational complexity, and it increased interpretability of rules. The designed fuzzy logic controller implemented to the Quanser experimental set. Comparison of the proposed method with the designed LQR controller reveals the efficiency of it. The suggested fuzzy controller not only decreased tracking error significantly but also overshoot in the deflection angle is more acceptable in comparison to LQR controller. Result shows efficiency of proposed controller in trajectory tracking of desired trajectories.

\section{Acknowledgments}

Authors are much grateful to Dr. Faezeh Farivar, a member of the ISLAB of the K. N. Toosi University, for her guidance and enthusiasm. Also, they are indebted to the Intelligent System Laboratory (ISLAB) of the K. N. Toosi University for the support provided during this study.

\section{References}

[1] M. W. Spong and M. Vidyasagar, Robot Dynamics and Control, Wiley, New York, NY, USA, 1989.

[2] S. E. Talole, J. P. Kolhe, and S. B. Phadke, "Extended-stateobserver-based control of flexible-joint system with experimental validation," IEEE Transactions on Industrial Electronics, vol. 57, no. 4, Article ID 5210149, pp. 1411-1419, 2010.

[3] F. M. Botsali, M. Kalyoncu, M. Tinkir, and U. Onen, "Fuzzy logic trajectory control of flexible robot manipulator with rotating prismatic joint," in Proceedings of the 2nd International Conference on Computer and Automation Engineering (ICCAE'10), pp. 35-39, February 2010.

[4] M. A. Ahmad, "Vibration and input tracking control of flexible manipulator using LQR with non-collocated PID controller," in Proceeding of 2nd UKSIM European Symposium on Computer Modelling and Simulation, pp. 40-45, September 2008.

[5] W. Yim, "Adaptive control of a flexible joint manipulator," in Proceedings of the IEEE International Conference on Robotics and Automation (ICRA '01), pp. 3441-3446, May 2001.

[6] J. H. Oh and J. S. Lee, "Control of flexible joint robot system by backstepping design approach," in Proceedings of the IEEE International Conference on Robotics and Automation (ICRA '97), vol. 4, pp. 3435-3440, April 1997.

[7] F. Ghorbel, J. Y. Hung, and M. W. Spong, "Adaptive control of flexible-joint manipulators," IEEE Control Systems Magazine, vol. 9, no. 7, pp. 9-13, 1989.

[8] L. C. Lin and K. Yuan, "Control of flexible joint robots via external linearization approach," Journal of Robotic Systems, vol. 7, no. 1, pp. 1-22, 2007.

[9] M. W. Spong, K. Khorasani, and P. V. Kokotovic, "An integral manifold approach to the feedback control of flexible joint robots," IEEE Journal of Robotics and Automation, vol. 3, no. 4, pp. 291-300, 1987.

[10] P. Tomei, "A simple PD controller for robots with elastic joints," IEEE Transactions on Automatic Control, vol. 36, no. 10, pp. 1208-1213, 1991.

[11] J. S. Yeon and J. H. Park, "Practical robust control for flexible joint robot manipulators," in Proceedings of the IEEE International Conference on Robotics and Automation (ICRA '08), pp. 3377-3382, May 2008.

[12] M. A. Ahmad, R. M. T. Raja Ismail, M. S. Ramli, and M. A. Zawawi, "Elastic joint control using non-collocated fuzzy and filtering scheme: a comparative assessment," in Proceedings of the 4th Asia International Conference on Mathematical/Analytical Modelling and Computer Simulation, pp. 366-371, May 2010.

[13] M. A. Ahmad, M. H. Suid, M. S. Ramli, M. A. Zawawi, and R. M. T. Raja Ismail, "PD fuzzy logic with non-collocated PID approach for vibration control of flexible joint manipulator," in Proceedings of the 6th International Colloquium on Signal Processing and Its Applications (CSPA '10), May 2010.

[14] A. Jnifene and W. Andrews, "Experimental study on active vibration control of a single-link flexible manipulator using tools of fuzzy logic and neural networks," IEEE Transactions on Instrumentation and Measurement, vol. 54, no. 3, pp. 12001208, 2005.

[15] M. A. Ahmad, R. M. T. Raja Ismail, M. S. Ramli, M. A. Zawawi, N. Hambali, and N. M. Abd Ghani, "Vibration control of flexible joint manipulator using input shaping with PD-type fuzzy logic control," in Proceedings of the IEEE International Symposium on Industrial Electronics (ISIE '09), pp. 1184-1189, July 2009.

[16] M. A. Ahmad, R. M. T. R. Ismail, and M. S. Ramli, "Optimal control with input shaping for input tracking and vibration suppression of a flexible joint manipulator," European Journal of Scientific Research, vol. 28, no. 4, pp. 584-600, 2009.

[17] M. A. Ahmad, M. S. Ramli, R. M. T. Raja Ismail, N. Hambali, and M. A. Zawawi, "The investigations of input shaping with optimal state feedback for vibration control of a flexible joint manipulator," in Proceedings of the Conference on Innovative Technologies in Intelligent Systems and Industrial Applications (CITISIA '09), pp. 446-451, July 2009.

[18] F. Farivar, M. A. Nekoui, M. A. Shoorehdeli, and M. Teshnehlab, "Sliding mode control of flexible joint using Gaussian Radial Basis Function Neural Networks," in Proceedings of the International Conference on Computer and Electrical Engineering (ICCEE '08), pp. 856-860, December 2008.

[19] S. Ozgoli and H. D. Taghirad, "Design of composite control for flexible joint robots with saturating actuators," in Proceedings of the 5th Iranian Conference on Fuzzy Systems, pp. 75-82, 2004.

[20] M. R. Kandroodi, F. Farivar, M. Z. Pedram, and M. A. Shoorehdeli, "Variable structure control and anti-control of flexible joint manipulator with experimental validation," in 
Proceedings of the IEEE Intemational Conference on Mechatronics, pp. 294-299, 2011.

[21] H. Chaoui, P. Sicard, and A. Lakhsasi, "Reference model supervisory loop for neural network based adaptive control of a flexible joint with hard nonlinearities," in Proceedings of the Canadian Conference on Electrical and Computer Engineering, pp. 2029-2034, May 2004.

[22] D. Hui, S. Fuchun, and S. Zengqi, "Observer-based adaptive controller design of flexible manipulators using time-delay neuro-fuzzy networks," Journal of Intelligent and Robotic Systems: Theory and Applications, vol. 34, no. 4, pp. 453-466, 2002.

[23] B. Subudhi and A. S. Morris, "Singular perturbation based neuro- $\mathrm{H} \infty$ control scheme for a manipulator with flexible links and joints," Robotica, vol. 24, no. 2, pp. 151-161, 2006.

[24] "Quanser Student Handout, Rotary Flexible Joint Module," http://www.quanser.com. 

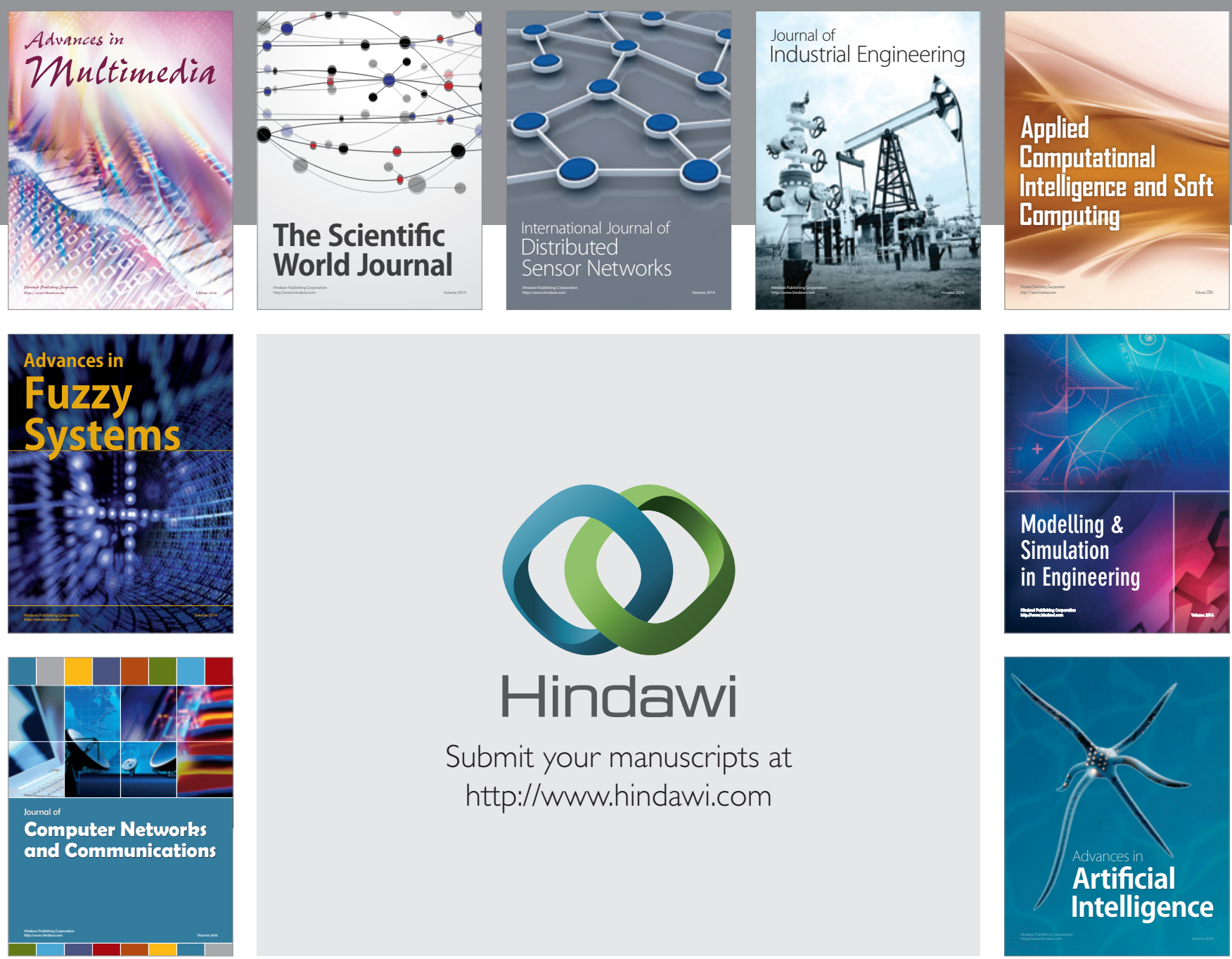

Submit your manuscripts at

http://www.hindawi.com
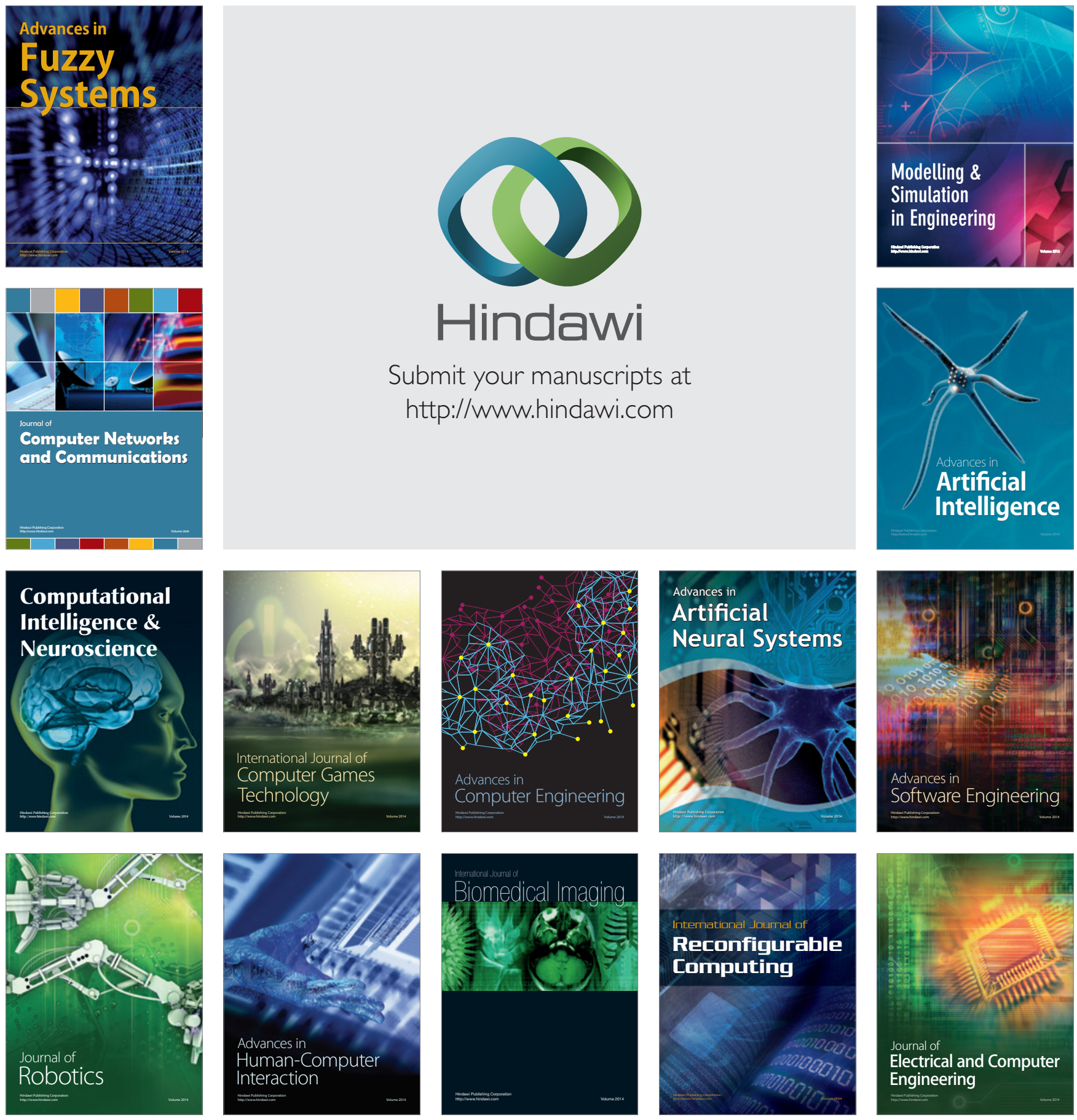